\title{
THE GROWTH OF BALANUS BALANOIDES (L.) AND B. CRENATUS BRUG. UNDER VARYING CONDITIONS OF SUBMERSION
}

\author{
By H. Barnes and H. T. Powell \\ The Marine Station, Millport
}

(Text-figs. I-7)

There is some information in the literature on the growth rate of Balanus balanoides (L.) under varying natural conditions, but very few comparable data on B. crenatus Brug. exist. Most of this work relates to natural populations where crowding and other factors make accurate measurement difficult. In general, samples of a population, sometimes of unknown or only estimated age-distribution, have been measured at intervals. In the work reported below, the growth of numerous individual barnacles of known age, exposed to both intertidal conditions and complete submersion, has been followed through several successive seasons at Millport. In addition, some observations are presented on the effect of tidal level on the intensity of settlement and subsequent mortality of $B$. balanoides.

\section{The Experimental Methods}

For the intertidal exposures (B. balanoides only), seven $15 \times$ Io in., rough, black, plastic panels were bolted on to a long metal frame which was lashed in a fixed vertical position to the outer face of a pier pile, the position of each panel in relation to Chart Datum being calculated from known Ordnance Datum. The level of the centre of each panel is shown in Table I.

Observations during periods of calm weather at the site have shown that, in general, there is a closer agreement between the heights actually reached and those predicted for Greenock from new data in the Admiralty Tide Tables for 1952 (I95I), than with the values obtained by applying the corrections given for Millport. Mean tidal levels at the site, relative to Chart Datum, are therefore similar to those for Greenock, which are as follows: M.H.W.S., + II.I ft.; M.H.W.N., +9.3 ft.; M.T.L., +6.2 ft.; M.L.W.N., + 3.2 ft.; M.L.W.S., $+\mathrm{I}: \mathrm{I}$ ft. The hours of exposure and submergence at the centre of each panel over the actual period of settlement (also shown in Table I), and over a typical full lunar period (data for Figure 4), were calculated from graphs of the tidal cycle drawn up from data for Greenock in the Admiralty Tide Tables for 1951 (I950), with a correction based on the new mean levels given in the 1952 tables. Anemometer records near the site show that wind speeds during the 
period of settlement were low and therefore the effect of wind on tidal levels has been neglected.

For the permanently submerged settlement (including both $B$. balanoides and $B$. crenatus), plain and ground glass slides of several sizes were exposed in a vertical position at a constant depth of $3 \mathrm{ft}$. from a nearby raft, a description of which has been given by Pyefinch (1948).

\section{Table I. Settlement of BALANUS BALANOIDES on Intertidal Panels 6-26 APRIL I95I}

- The levels refer to the centres of panels and are given in feet relative to Chart Datum; the number of cyprids refer to the upper, middle and lower thirds of each panel, together with total numbers; the tides across are the number of times the water surface passed the centre of the panel each way during the settling period; exposure and submergence in hours and percentage of total (see text).

\begin{tabular}{|c|c|c|c|c|c|c|}
\hline \multirow{3}{*}{$\begin{array}{c}\text { Panel No. } \\
\text { I } \\
\text { II }\end{array}$} & \multirow{3}{*}{$\begin{array}{l}\text { Level } \\
+ \text { I0. } 8 \\
+8.9\end{array}$} & \multicolumn{2}{|c|}{ Cyprids } & $\begin{array}{l}\text { Tides } \\
\text { across }\end{array}$ & Exposure & Submergence \\
\hline & & 0 & o & 34 & 460 & $30(6 \%)$ \\
\hline & & $\left.\begin{array}{r}50 \\
154 \\
159\end{array}\right)$ & 363 & 76 & 368 & I $22(25 \%)$ \\
\hline III & $+7 \cdot 2$ & $\left.\begin{array}{r}1077 \\
670 \\
565\end{array}\right\}$ & $23 \mathrm{I} 2$ & 80 & 283 & $207(42 \%)$ \\
\hline IV & $+5 \cdot 4$ & $\left.\begin{array}{r}2509 \\
1077 \\
564\end{array}\right\}$ & 4150 & 80 & 212 & $278(57 \%)$ \\
\hline V & $+3 \cdot 6$ & $\left.\begin{array}{r}425 \\
254 \\
38\end{array}\right\}$ & 717 & 74 & I32 & $358(73 \%)$ \\
\hline VI & $+\mathrm{I} \cdot 8$ & $\begin{array}{r}1837 \\
555 \\
148\end{array}$ & 2540 & 46 & 47 & $443(90 \%)$ \\
\hline VII & 0.0 & $\left.\begin{array}{l}806 \\
174 \\
169\end{array}\right\}$ & I I 49 & 0 & o & $490(100 \%)$ \\
\hline
\end{tabular}

On all panels, after a quantity of spat had settled, the positions of a number (20-40 per set) of selected barnacles, uniformly distributed over the panels, were marked and these barnacles were thereafter measured at intervals. When in the laboratory for measurements, the panels and slides were kept in running sea water except while actually being measured and, with very few exceptions, were returned to the exposure sites within $24 \mathrm{hr}$. At each inspection the panels and slides, and with the older barnacles the surfaces of the barnacles themselves, were cleaned of debris, algae and settled animals.

Three dimensions were measured: the rostro-carinal axis (termed length), the greatest diameter at right angles to the length (termed breadth), and the perpendicular height of the tallest compartment (usually the carina) above the basis. The third dimension was measured on only a limited number of inspections, but the first two were measured throughout the observations. In the early stages of growth on both the large intertidal panels and the small submerged slides the lengths and breadths of the barnacles were measured 
by means of a binocular microscope with low-power objective and an eyepiece micrometer. In the later stages on the submerged slides a verniermeasuring microscope was used. Heights of the submerged barnacles were measured throughout with a micrometer screw-gauge, allowance being made for the thickness of the slide. The use of small slides greatly facilitated accurate measurement of the submerged barnacles, but led in later stages of growth to the necessary sacrifice of some individuals which had to be removed to prevent overcrowding and consequent distortion of growth. With the intertidal barnacles, heights, and at the later inspections length and breadth also, had to be measured as accurately as possible with a pair of fine pointed dividers, because of the large size of the panels.

The observations on the submerged barnacles extended continuously from April I950, and on the intertidal barnacles from April I951, to October I952, readings being taken monthly during periods of rapid growth.

In most studies of barnacles increase in length of the rostro-carinal axis has been used as a measure of growth (see p. I20). Moore (I934), however, measured length, breadth and height and computed the volume of an equivalent cone of basal diameter equal to the mean of the length and breadth, and with the measured height. As Moore points out, the increase in size of the whole animal is obviously better measured by volume changes, but since, as will be shown, the shape does not change greatly with age, for many purposes the length may be conveniently used. However, the fact that length has been used must be borne in mind; the volume will approximate to a function of the cube of the length. The advantages of using the length are that it does not involve any assumptions about length/volume relationship, and that the present results are more readily compared with those of other workers. Further, it is a convenient method for field work since the length can be measured quickly and with reasonable accuracy.

\section{Settlement and SuRvival on the Intertidal Panels}

In I95I the first settlement of $B$. balanoides was observed on the pier piles and on the shore on Io April, and settlement continued during the remainder of this month. The panels were exposed throughout this period, during which several inspections were made. At none of the inspections were any cyprids found on the topmost panel (Panel I, level + I0.8 ft.), although settlements took place on all of the remaining panels (II-VII). Before marking the selected barnacles on 27 April the distribution of all the cyprids and young barnacles on each panel was ascertained. In Table I (p. I08) the distributions (dividing the panels into upper, middle and lower thirds) are shown. With the exception of Panel V (level $+3.6 \mathrm{ft}$.), the total settlement is much less on Panel II than on the remainder; that on Panel V is apparently anomalous, and the only explanation that can be put forward is that it is 
the result of different local conditions in the immediate vicinity of this panel brought about by a diagonal pier beam immediately behind the frame.

The numbers actually counted on any panel will represent the net result of cyprid settlement and mortality. It might be thought that cyprid settlement would increase with total submergence, and that the number of cyprids settling would be greater as the depth of panels increased. This is clearly at variance with the results (see Table I), and it seems difficult to find any neutralizing effect by which mortality could produce the observed net results in relation to panel depth. Exposure (to air), which might be expected to be the major factor responsible for cyprid mortality, since it is inversely related to submergence, clearly cannot produce the observed net result. The following theory is put forward to explain the observed distribution. Although it is known that $B$. balanoides will settle on a permanently submerged surface (indeed, quite good settlements are recorded here), under natural conditions it is usually an intertidal species and undoubtedly the greatest settlement takes place within the littoral zone. It is postulated that intertidal settlement takes place most readily from a thin layer of water, such as is normally obtained when water moves forwards and backwards over a solid surface. On vertically exposed panels this occurs while the tide is rising and falling past the panel. During this process the surface of the panel is continually being swept by films of water that drain away. The 'clinging reaction' of B. balanoides cyprids described by Pyefinch (I948) (in contrast to B. crenatus, which is mainly a sublittoral species) lends support to this hypothesis. On this basis, the important factor for settlement is the number of times the tide crosses the surface of the panel; this will be maximal in the centre of the tidal range, and less at the upper and lower levels (see Table I), and would lead to maximal settlement in the mid-tidal region. The major factor opposed to that producing settlement is considered to be mortality of cyprids caused by exposure to air, and the hours of exposure at the various levels during the period under consideration are shown in Table I. The low numbers on Panel II are therefore largely the result of high mortality consequent upon the very considerable exposure to air. The differences on Panels III and IV are due to the decreasing exposure factor, and the lower values on Panels VI and VII are due largely to the less frequent crossing of the panel by the tide, since the exposure factor and consequent mortality is here greatly reduced. The actual relation between exposure to air and mortality over the settling period is not quantitatively known, but mortality of cyprids and young barnacles is known to have been very high on Panel II. However, it is quite clear from the figures in Table I that the opposition of these two factors can produce a maximal net settlement about the level of mid-tide, in accordance with the observed results. A similar distribution of the settlements of B. balanoides over the littoral zone has been observed by other workers (see, for example, Hatton \& Fischer-Piette, I932; Moore, I935b; Hatton, 1938). An extension 
of this hypothesis would also seem capable of explaining in part the well-known fact that $B$. balanoides tends to settle in greater numbers in situations with considerable exposure to wave action. In such places, increased surge and breaking waves will repeatedly spread a thin layer of water over a larger area than in sheltered situations.

The complete lack of survival on Panel I must be due to the extremely high exposure factor; but at this level on the adjacent pier pile, which is just above the upper limit of $B$. balanoides in quantity ( $10.2 \mathrm{ft}$.), a very slight permanent new settlement was observed, and this is ascribed to the rougher surface texture of the wooden piles. Such a surface affords a better key for settlement (see Barnes, Crisp \& Powell, I95I), and also is less easily desiccated (see Pomerat \& Reiner, I942; Pomerat \& Weiss, I946; Barnes \& Crisp, I953).

A further noticeable feature of the settlement, with the exception of the high-level Panel II, is the distinctly greater settlement on the upper third of each panel (see Table I). This can readily be explained in terms of a light response, since it has been shown (Barnes et al. I95I) that the crawling cyprids react positively to light, and this accumulation could therefore be the result of the general movement of the cyprids up the vertical panels. Further, the accumulation is most marked on the lower panels, and perhaps may be related to the total submersion time, longer periods of submersion allowing more time for migration.

\section{Mortality of Marked Barnacles}

Of the forty-seven marked barnacles uniformly distributed on Panel II (situated at about M.H.W.N. level) all except ten were dead after I month's exposure. Only four survived 2 months' exposure and these continued to grow slowly (see below) until late summer. They were all absent by October and there was no evidence of any accident or predation; so that, although this is below the level at which barnacles occur in quantity on the adjacent pier piles, conditions on the smooth panel during the higher summer air temperatures were apparently too severe for survival.

On the remaining panels all the marked barnacles, except those deliberately removed to prevent overcrowding, survived for at least I year. It should be remembered that all panels were kept free of such predators as Nucella lapillus (L.) and Asterias rubens L. However, in July of the second season many were dead, probably as a result of infection by the parasitic isopod Hemioniscus balani (Spence Bate). The resultant mortality was $56 \%$ on the uppermost panel at this time (Panel III) and $20 \%$ on the lower panels (IV-VII), and these figures indicate that this parasitism may here not only cause considerable mortality of adult barnacles, but also exert a differential effect with respect to tidal level. Prenant (I923) records that approximately $20 \%$ (which he regards as a minimum) of Balanus balanoides growing on rock masses near Roscoff were parasitized by Hemioniscus balani. 


\section{Seasonal Growth and Specific Growth Rates \\ Balanus crenatus on Submerged Panels}

Pyefinch (I948) has pointed out that, although the major liberation of nauplii and subsequent settlement of cyprids takes place in the spring in this area, ripe larvae are present in a proportion of the adults (although in diminishing numbers) throughout the summer; periodic outbursts of cyprid larvae are found in the plankton throughout the summer and early autumn. In I950, when the present observations were begun, quite considerable settlements took place during the late summer and autumn-as late as October.

In all, the growth of seven distinct settlements was followed throughout three successive seasons. For comparison of growth each settlement (Series I-VII) has been considered separately, and the mean length and standard error calculated for each Series at each date of observation; the mean lengths are plotted against age in Fig. I.

It is clear from the figure that rapid growth occurs after metamorphosis, and increase in length continues during the spring and summer months. In the animals settling from mid-April to mid-June (Series I-IV, termed Group I) growth continued until mid-September, by which time the mean length of the earliest settlers (Series I) had reached $2 \mathrm{I} \cdot 7 \mathrm{~mm}$. and this was only a few millimetres less than the maximum mean length attained over three seasons; the later Series IV of this Group had reached a mean length of $17.7 \mathrm{~mm}$. by mid-September of the first season. In none of this Group was any significant growth recorded after mid-September, that is during the first autumn and winter. The second season's growth did not begin until the latter half of May I95I, a month later than the time at which rapid growth began in the previous season. In the second season the same general growth pattern was repeated in Group I but with greatly reduced intensity, growth taking place during the summer and ceasing in the autumn. The mean increase in length, however, was very small during this second season, not exceeding 4-5 mm.: clearly Group I individuals had almost reached their maximum size in the first season's growth.

Series V-VII (Group II) settled during the summer and autumn of I950. Growth followed settlement as with the spring spat but, in marked contrast, increase in length continued much longer, some being recorded in late autumn and winter (October to December). Indeed Group I had virtually ceased to grow before the settlements of Series VI and VII occurred. Further, in sharp contrast to Group I, the latest settled individuals (Series VII) were showing some growth between January and February of the following season, more growth from February to March and rapid growth, comparable with the initial growth of the earliest settlements of the previous year, from March to April. Growth continued until early autumn of the second year, when the barnacles appeared to have reached their maximum size, which was com- 


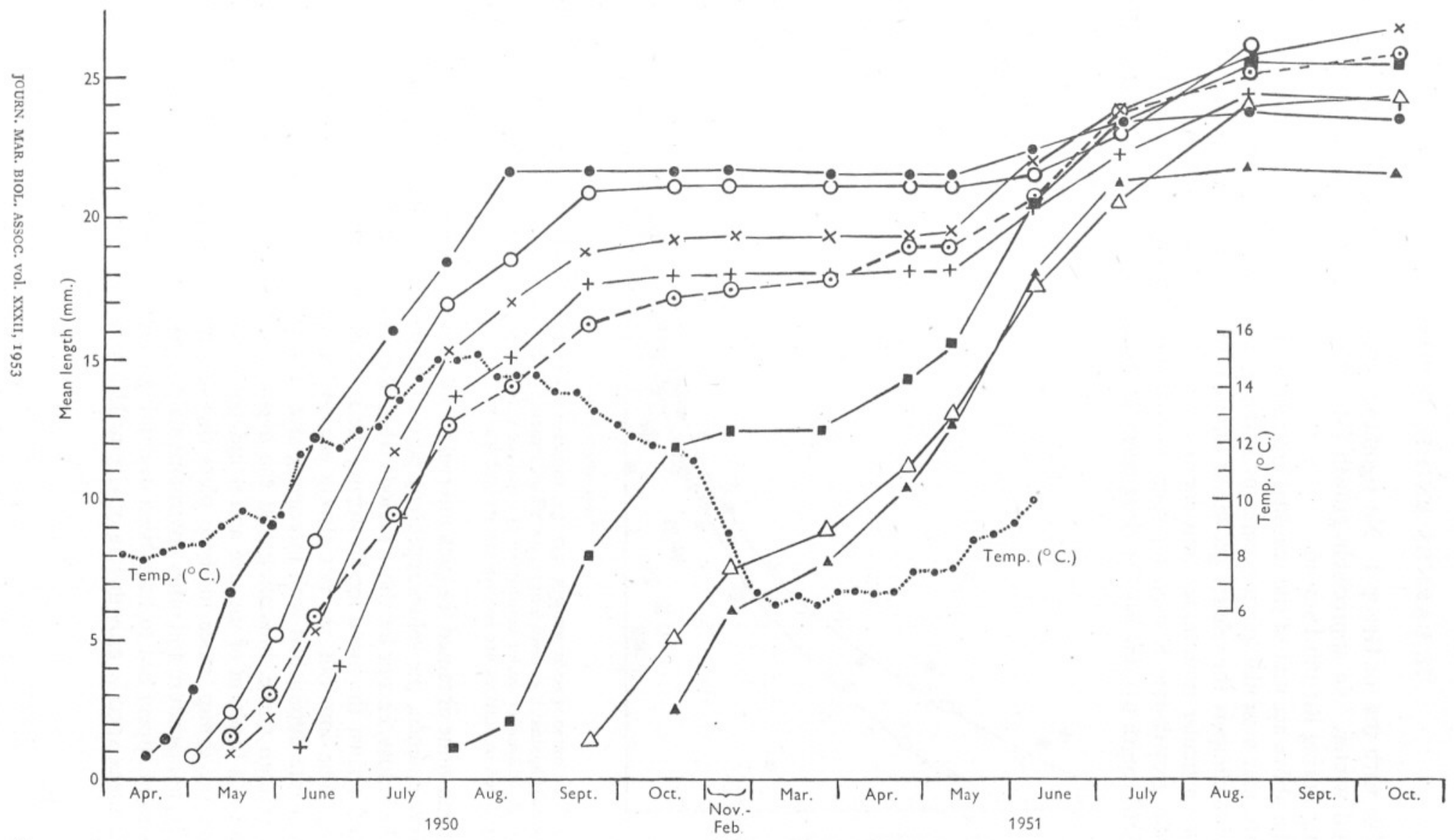

Fig. I. Growth of Balanus crenatus and of B. balanoides over several seasons under conditions of total submersion. The mean lengths of each settlement (Series I-VII) at each date of inspection are shown: the almost negligible growth in the third season is omitted. The weekly mean sea-water temperatures ( ${ }^{\circ}$ C.) are also shown. B. crenatus: Series I, $\bullet$ II, O; III, $\times$; IV, +; V, 国; VI, $\triangle$; VII, $\mathbf{\Delta}$; B. balanoides, $\odot$. 
parable with that of Group I. No significant growth took place during the second winter. No appreciable growth $(<\mathrm{I} \cdot 0-2 \cdot 0 \mathrm{~mm}$.) occurred in either Group during the third season.

The above account of the seasonal growth has been based on increases in length, and a similar picture emerges if the breadth is used. However, in order to compare the relative growth at different times, the size of the animal at the particular time under consideration must be taken into account. The specific growth-rate is used for such comparisons. The increase in length per unit length per day has therefore been calculated for each individual and

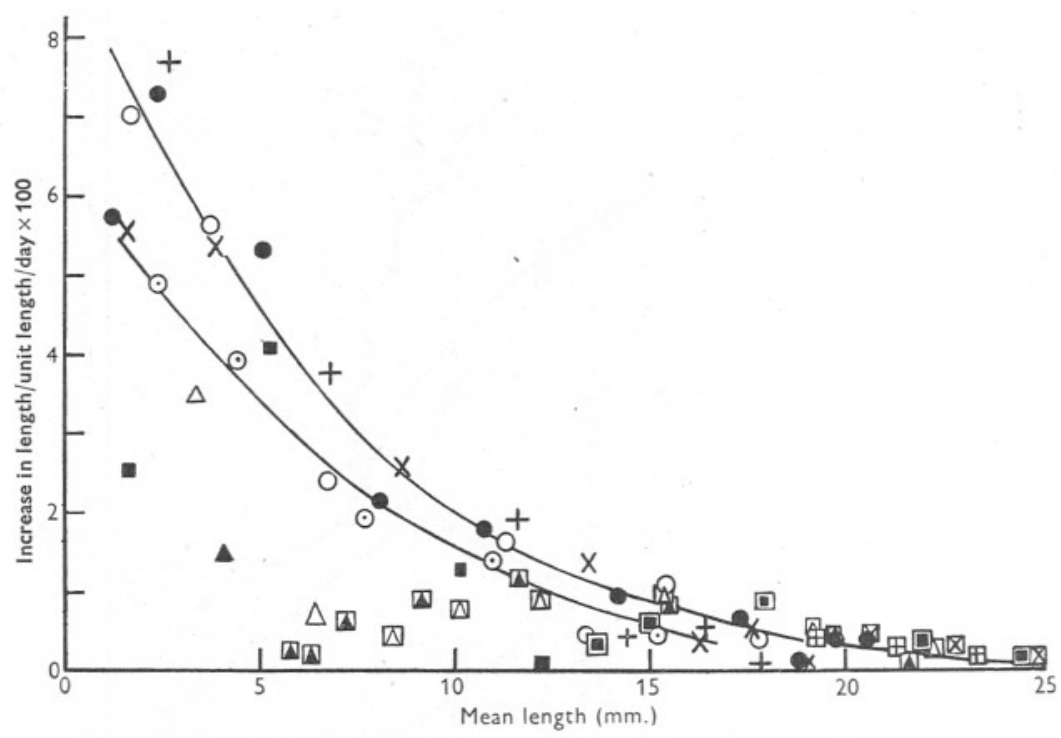

Fig. 2. The mean specific growth-rate (i.e. increase in length per unit length per day) $\times$ Ioo, plotted against the mean length, for all settlements of $B$. crenatus and a single settlement of B. balanoides under conditions of constant submersion. Symbols as in Fig. I; those enclosed in squares are records for second season.

the mean value obtained for each interval for all Series. (If multiplied by Ioo, for convenience, the values represent percentage increase in length per day.) All the values, except for those periods when there was no increase in length, plotted against the mean length during the interval concerned, are shown in Fig. 2. The intervals are not always exactly the same. The mean specific growth-rate diminished with increasing size. The points for Group I all fall on a smooth curve, indicating that the mean specific growth-rate over this period is a function of the size and is independent of the time of settlement within the group, since in these plots the ages are not considered. Food supply, temperature and other environmental factors which varied throughout the season appear not to have been overriding factors. However, the values of the mean specific growth-rate of Group II late in the season are less than 
the corresponding values for Group I at the same length in the spring and early summer, suggesting that environmental factors were effective in limiting growth late in the season (see p. I24). Further, in the second season the mean specific growth-rates of Group II in the very early spring are less than those of Group I at the same size, growing rather later in the previous season. Indeed, during the latter part of the spring of the second season's growth, the mean specific growth-rate of Group II actually rises with an increase in mean length.

\section{Balanus balanoides on Intertidal and Submerged Panels}

In contrast to B. crenatus, there is only one liberation of nauplii during the year, and the settlement of cyprids usually takes place over the latter part of March and throughout April. There is therefore nothing comparable with the seven Series of $B$. crenatus, but only observations on the growth of a single

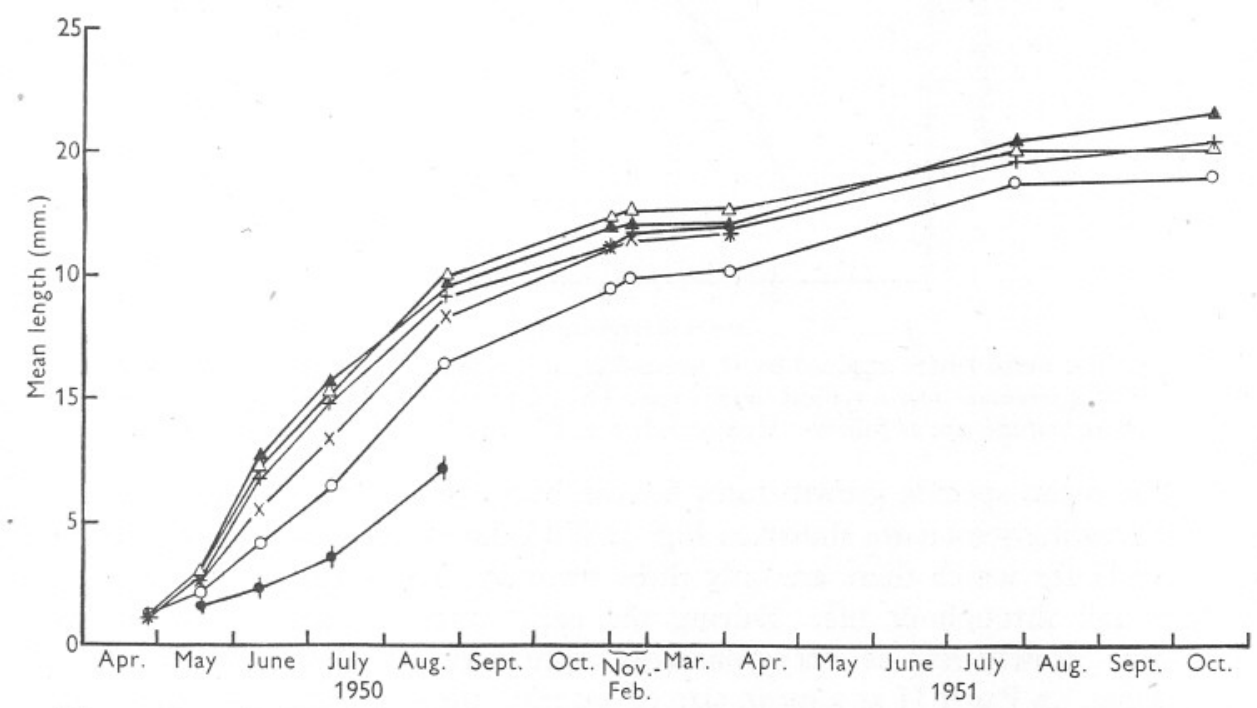

Fig. 3. Growth of B. balanoides over two seasons on intertidal panels II-VII (see Table I), The mean lengths on each panel at each date of inspection are shown. Panel II, $\boldsymbol{~ ; ~}$ III, O; IV, $\times$; V, + ; VI, $\triangle$; VII, $\boldsymbol{\Delta}$.

settlement for each panel at different tidal levels. The mean lengths plotted against age are shown in Figs. I and 3. It should be remembered that growth of the intertidal barnacles was measured in the season following the observations on the submerged barnacles. The growth pattern is similar to that just discussed for $B$. crenatus. Increase in length takes place throughout the spring and summer months, but in contrast, some growth, although very small, appears to continue throughout the first winter on the intertidal panels, this continued growth being more marked on the upper panels where the 
barnacles were smaller. In the second season growth continued on all panels. By October of the first season the mean length attained by $B$. balanoides on the submerged exposures was $17.2 \mathrm{~mm}$., and on the intertidal panels the mean length varied from $17.3 \mathrm{~mm}$. on the lower Panel VII to $14.4 \mathrm{~mm}$. on the upper Panel III (no barnacles remaining on Panel II at this date). Complete submersion has thus given optimum conditions for growth, and the growth on the lower intertidal panels closely approaches that for complete submersion. This is clearly brought out in Fig. 4 in which the mean length attained by 24 August 195I (i.e. after approximately 4 months' growth) is plotted against the hours of submersion during one typical full lunar period.

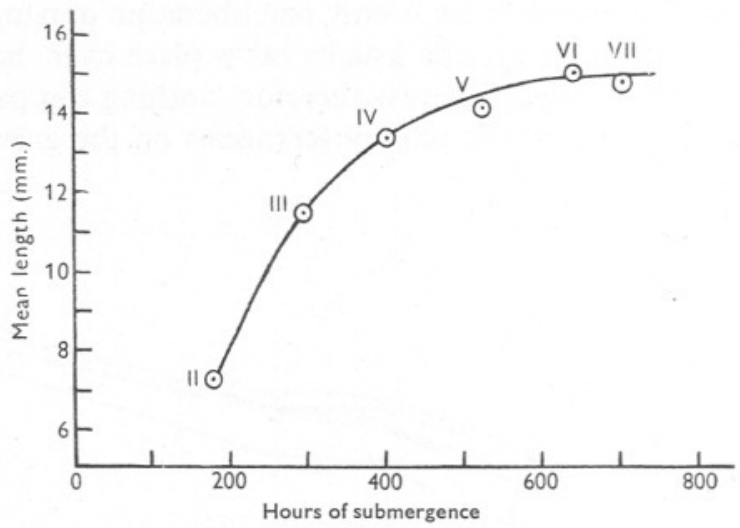

Fig. 4. The mean length attained by $B$. balanoides on intertidal panels, plotted against hours of submergence over a typical lunar cycle. The heights of the Panels, in feet (relative to Chart Datum) are as follows: II, $8 \cdot 9$; III, $7 \cdot 2$; IV, $5 \cdot 4$; V, $3 \cdot 6$; VI, I.8; VII, 0.0.

The mean specific growth-rates for the barnacles on each panel over the first growing season are shown in Fig. 5. With the exception of the high level Panel II for which there are only three readings, the mean specific growthrates fall throughout life. During the early stages of growth the mean specific growth-rate is very markedly influenced by the exposure. For example, on Panel II at a mean size of $2.0 \mathrm{~mm}$. the specific growth-rate was 0.014 I, while on Panel VII at $2.17 \mathrm{~mm}$. it was 0.0387 , and on the totally submerged panels at a mean length of $2.37 \mathrm{~mm}$. it was 0.0489 . The other intertidal panels give values intermediate between these extremes. At the levels of Panels V-VII there is little evident distinction between the growthrates, although the points lie below those for complete submersion (raft) derived during the previous year. The mean specific growth-rates, however, fall more steeply on those panels with greater submersion, so that by the time a size of about $9 \mathrm{~mm}$. is reached the mean specific growth-rate and the change of mean specific growth-rate with increasing length have become virtually identical, and at a slightly increased length are coincident with the values for complete submersion. 
Apparently B. balanoides, unlike B. crenatus, does not reach its virtual maximum size in a single season, and therefore it is not surprising to find that the length began to increase significantly quite early in the second season and that relatively more growth took place during the second season, even though this was small in comparison with the first season's growth. Thus on the submerged panels there was an increase in the mean length from $17 \cdot 2$ to $25.8 \mathrm{~mm}$. from October 1950 to October I95I, that is during the second

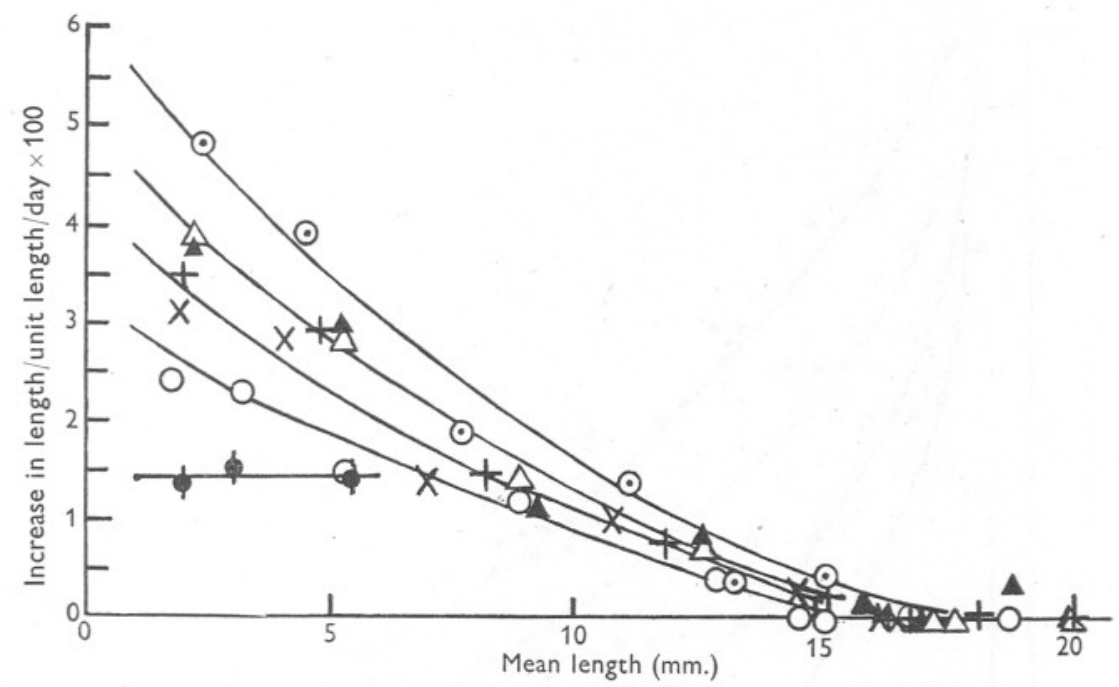

Fig. 5. The mean specific growth-rate (i.e. increase in length per unit length per day) $\times 100$ plotted against mean length, for B. balanoides on intertidal Panels II-VII, together with that for the completely submerged specimens for the previous year. Symbols as in Fig. 3; submerged $B$. balanoides shown as dot-and-circle.

season, and even a slight increase to $26.3 \mathrm{~mm}$. during the third season, whereas in the intertidal exposures the second season's increase in length was of the order of $4 \mathrm{~mm}$. (the maximum mean length reached at the end of the second season was $21.7 \mathrm{~mm}$. on Panel VII and I9. I mm. on Panel III), the relative increase being greatest on the higher panels where there had been only slow growth in the first season.

\section{The Length, Breadth and Height Relations during Growth}

Runnström (1925) has stated that B. balanoides at Herdla were relatively higher in the second than in the first year, but he gives no measurements. Moore (1934) observed no change in the apical angle of individuals on the shore, but recorded a change in others growing under estuarine conditions.

The periodic measurement of length, breadth and height of individuals in the present work allows the possibility of such changes in shape to be investigated. 
For all raft and intertidal exposures the length/breadth and length/height ratios were calculated for each individual on each separate date of inspection during the growing period; the mean values of the ratios and their standard errors were then found for each set on all the inspections. In Figs. 6 and 7 these mean ratios are plotted against the appropriate mean length: the pooled standard error of the means is also shown. The curves were drawn by inspection.

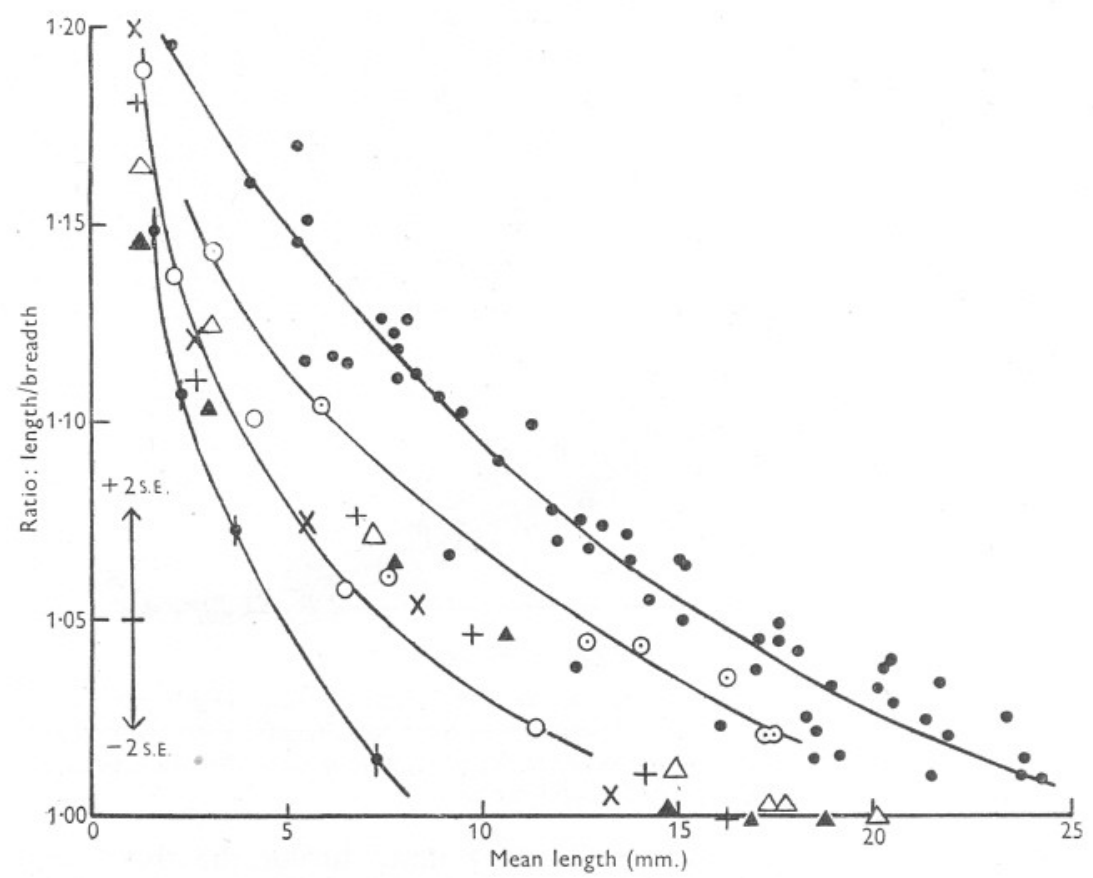

Fig. 6. The mean ratio of length to breadth plotted against mean length for B. crenatus totally submerged and $B$. balanoides on intertidal and totally submerged panels. Limits of $2 \times$ standard error shown by arrows. B. crenatus, all series shown as black circles, since there was no significant difference in ratio (see text); B. balanoides, as in Fig. 5 .

No account is taken of age in these Figures. With B. crenatus, with its several Series, the barnacles represented for a given mean length are often of quite different total age, as a result of taking into account all the settlements which were spread over several months.

B. crenatus will be considered first. Fig. 6 indicates that the length/breadth ratios decrease with increasing size and, within the limits of random sampling errors, can be considered to lie on a single curve, i.e. there is no indication that the ratio changes from Series to Series: in other words, the ratio is not a function of the time since settlement but only of the size attained by the animal. The rate of change of the ratio with length is greater at the lower 
mean lengths, i.e. during the period of most vigorous growth (see p. II2). The total change in the mean ratio is not great, from $\mathrm{I} \cdot 200$ at a mean length of $2 \mathrm{~mm}$. to I.OIO at a mean length of $24 \mathrm{~mm}$. In terms of change of shape, this decrease in the ratio with increasing size means that throughout growth the outline of the base changes, most rapidly at first, from more or less elliptical to almost circular. (If the actual cyprid itself were considered then the initial change would be greater.)

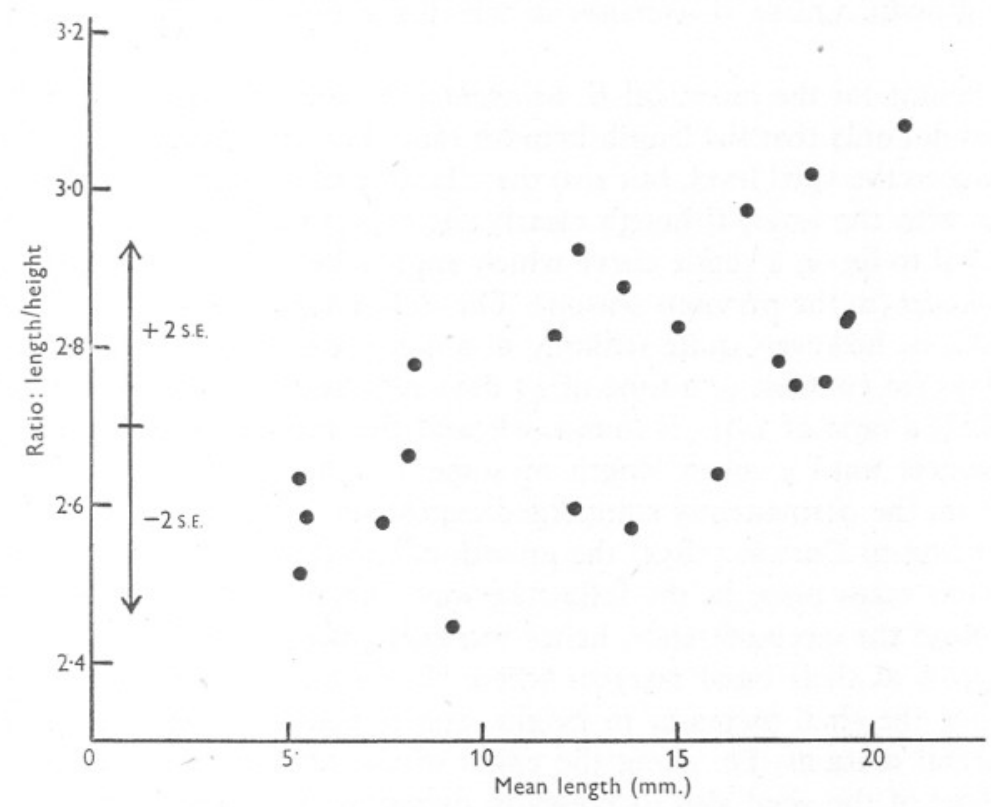

Fig. 7. The mean ratio of length to height plotted against mean length for totally submerged $B$. crenatus. Limits of $2 \times$ standard error shown by arrows.

The method of measuring the height is far less accurate and satisfactory than that of the length and breadth, for the upper part of the compartments, particularly of the carina which was usually measured, is liable to damage. These inaccuracies are reflected in the large standard errors, the pooled value of which was 0.II9, compared with a value of 0.0I4 for the length/breadth ratio. However, quite clearly the ratio increases with increasing mean length, the barnacles becoming relatively squatter as they become older. As far as can be ascertained, the relation is linear throughout the growth of the barnacle.

The form of the curve for length/breadth ratio of submerged $B$. balanoides plotted against mean length is similar to that for $B$. crenatus, that is, there is a decrease in the ratio as the animal increases in size, and the rate of change of the ratio with length decreases with increasing size of the barnacle. Again, therefore, there is a change from an elliptical to a circular outline of the base. The values of the ratio at a given length all lie below those for B. crenatus at 
the same length and a separate curve has therefore been drawn for $B$. balanoides. The position of this curve, below that for B. crenatus, implies that at a given length $B$. balanoides is more circular than $B$. crenatus.

The length/height ratios for the submerged $B$. balanoides were too few to graph: the results again showed a wide spread. However, the value of the ratio at a length of $3 . \mathrm{I} \mathrm{mm}$. was 2.42 , at $6.0 \mathrm{~mm}$. 3.27 , and thereafter there was no significant change. The major change therefore took place very early during growth, unlike $B$. crenatus in which the ratio showed a progressive change.

The results for the intertidal B. balanoides are also shown in Fig. 6, which indicates not only that the length/breadth ratios at a given length tend to vary according to the tidal level, but also that the rate of change of the ratios also changes with the level, although clearly the values on Panels V-VII can be considered to lie on a single curve which approaches that for the submerged B. balanoides (in the previous season). The difference in Panel II, the highest of the set, is, however, quite striking: at a mean length of $7 \cdot 25 \mathrm{~mm}$. reached in 98 days (in contrast to a time of 45 days required to reach this length on Panel VII) a ratio of $\mathrm{I} \cdot 0 \mathrm{I} 5$ is found, whereas this ratio is not reached on the lower panels until a mean length of some $14 \mathrm{~mm}$. has been reached and I9 $\mathrm{mm}$. on the permanently submerged exposures.

According to Darwin (1854) the growth of the shell of a barnacle such as $B$. crenatus takes place in the following way. Accretions to the basis occur only around the circumference, hence increasing the diameter; the compartments grow at their basal margins where they are in contact with the base and hence the shell increases in height; the compartments also grow along their lateral margins, i.e. along the edges of the radii and alae, so that the upper part of the shell also increases in diameter. The foregoing results on the changes in shape imply that there are differential changes in the rate at which calcareous material is laid down during the life of the barnacle. For the length/breadth ratio to decrease during growth there must be a relative increase in growth-rate at the basal margins of the lateral compartments, as well as at the lateral parts of the calcareous basis in B. crenatus in order to maintain the continuity of the shell. The relative changes in height, which it should be remembered refer to the carinal compartment, also indicate changes in relative growth-rates in this part of the shell with respect to the overall length.

\section{SUMMARY OF LITERATURE ON GROWTH-RATE OF BALANUS BALANOIDES AND B. CRENATUS}

Runnström (1925), working at Herdla, has given data for the rostro-carinal diameter of intertidal $B$. balanoides over a period of 2 years, making no distinction with regard to tidal levels: the mean spring tidal range, however, 
is only $4 \mathrm{ft}$. The settlement took place in late April (29th) and growth followed during the first spring and early summer, but had almost ceased by July, by which time the mean length was only $3.0-4.0 \mathrm{~mm}$. He states that growth began again in October of the first year and by the following January the mean length was $7.0 \mathrm{~mm}$. Further growth apparently took place in the following spring and decreased very rapidly in the summer, at the end of which a mean size of $10.4 \mathrm{~mm}$. had been attained. He states that the first year is a vegetative year and that maturation during the second season is followed by fertilization in October, and the liberation of nauplii in the third spring. Further, he considered that $B$. balanoides lives for two years, occasionally three.

It is clear from Runnström's figures that individual barnacles were not followed, since the numbers measured at each inspection vary irregularly, e.g. on I5 February I925 twenty-six were measured, while on 7 April I925 IO2 were measured; and in view of this fact and the lack of data between July and October in the first season, it is doubtful if the information is sufficient to permit a critical assessment of the growth. Any marked growth during the period October to December of the first season would also seem to be somewhat doubtful. The spat was not followed into the second year but the growthrate over 2 years was deduced by the measurement of older individuals inferred to be of the second year-class from the different appearance of the shells due to algal infection (cf. Parke \& Moore, 1935). Indeed his graph, when the absence of data between 24 June and I5 October is taken into account, can be interpreted to follow quite closely the form of Figs. 2 and 4, with a gradual slowing of the growth in the late summer, although his actual growth-rates at any one time are very much smaller. The only real discrepancy is the period of rapid growth which he suggests takes place in the first midwinter and which, in view of the great similarity of environmental conditions (see below) and of the method of deriving these figures, i.e. from two entirely different sets of barnacles, may be questioned.

The $B$. balanoides measured by Moore (I934) were natural populations growing at the top, centre and near the bottom of their intertidal range. The growth was not measured from settlement and the actual ages of the barnacles were deduced. Indeed his growth curves extending over 3 years are hypothetical curves based on measurements over I year only. However, for the first year he indicates that rostro-carinal lengths of $5.2,5.3$ and $4.7 \mathrm{~mm}$. were reached on his upper, middle and lower patches, respectively. In addition, samples of his $\mathrm{O}$ and $\mathrm{Q}$ groups (of known age but from a level not specified) were measured and the growth curve for the $\mathrm{O}$ group is similar to those of the present investigation. Thus he found rapid growth from April to July, but virtually none during the late summer and winter, and that growth was renewed by May of the second season. There are no results from the early part of the second spring, so it is not known when the second season's growth began. Moore's other group $(\mathrm{Q})$ showed very little growth in the first season, 
and he suggests that they settled so late that their growth was retarded during the hot summer period.

Hatton \& Fischer-Piette (1932) have also studied the growth of intertidal $B$. balanoides, on blocks placed at a number of tidal levels and subject to varying conditions of wave-action, in the St Malo region. The rostro-carinal lengths were measured. Settlement in this region takes place from March to May and the graphs of two individual barnacles measured during two successive seasons (neglecting certain points which show a decrease in size and which are explained as due to erosion) show growth curves similar to those in Figs. 2 and 4. Rapid increase in length took place during the spring and slowed down between July and October. The pattern was repeated in the second season, but growth began between February and March. A length of about $3.0 \mathrm{~mm}$. was reached during the first season and $5.5 \mathrm{~mm}$. by the end of the second season. Further, Hatton \& Fischer-Piette point out that the greatest growth is at the lower levels where the animals are immersed for longer periods. Hatton (1938) confirms and extends these observations.

Corlett (1948) reporting on work in the Mersey estuary found that $B$. balanoides settling in April attained a mean rostro-carinal length of $5.9 \mathrm{~mm}$. by December of the first season, and $6.55 \mathrm{~mm}$. by the following April and states that growth was most rapid between May and September. $\mathrm{He}$ also records the occurrence of extremely large individuals $(20.35 \mathrm{~mm}$. mean length) of unknown age on concrete piles.

Fuller (I946) reports a mean length of $4.0,6.0$ and $8.0 \mathrm{~mm}$. in 4,8 and I 2 weeks respectively, for $B$. balanoides settling between May and July on panels exposed to continuous submersion at Frenchman's Bay, Maine; but he also records that the growth of barnacles settling a year later was much less, approximately $\mathrm{I} \cdot 0, \mathrm{I} \cdot 5$ and $2.0 \mathrm{~mm}$. in the same periods. He suggests that the smaller growth on the later occasion was due to the barnacles being situated on the lower surface of deep panels.

There are fewer data available for B. crenatus. Pyefinch (I948), working at Millport, has measured samples growing on panels submerged from a raft, and his figures expressing the modal lengths show rapid increase in length during the spring, with a falling off during the late summer and, by interpolation, a rapid growth in autumn of a late settled spat. He finds that the maximum size can be attained in the first season's growth as has been confirmed in the present observations. Topsent (I9II) states that at Luc-surMer, apparently in an intertidal, but low zone, B. crenatus can attain a size of $3.0-3.5 \mathrm{~mm}$. in 50-60 days, and 5.0-6.0 mm. after ro5 days.

Corlett (I948) found that Ioo specimens of B. crenatus, settled some time between late April and early July 1946, had a mean length of $5.6 \mathrm{~mm}$. (maximum II.5 mm.) by October I946; another group had a mean length of $6.6 \mathrm{~mm}$. (maximum II.0 mm.) in April I947.

Barnes \& Bagenal (I95I), studying B. crenatus settled on Nephrops nor- 
vegicus (L.), have deduced that spring-settling Balanus crenatus grow to a mean length of $4.4 \mathrm{~mm}$. by October and $8.5 \mathrm{~mm}$. by the following October, while those settling in the autumn showed some growth during the winter and reached a mean length of $\mathrm{I} .8 \mathrm{~mm}$. by January and $4.9 \mathrm{~mm}$. by the following July.

\section{Discussion}

When due account is taken of the methods of size estimation used by many workers on populations whose age was not accurately known, the results here presented seem to give a picture of the seasonal growth which is valid for all the regions from which results are available, from Herdla to St Malo and Luc-sur-Mer, and in the Gulf of Maine. This result is not surprising since the relative seasonal changes of water temperature and other environmental factors (with the possible exception of summer air temperatures) are not widely different in any of these regions.

Settlement in the spring is followed in both species by a rapid increase in length during late spring and early summer, after which the rate of increase in length falls off in the late summer and autumn and begins again during the following spring. In $B$. crenatus, under conditions of permanent submersion, the early spat appears to be able to reach a virtual maximum size in the first season, that is by October of the first year, and the small growth taking place in the second season begins somewhat later than in the first. In $B$. balanoides, however, on submerged panels, the maximum length is not reached in the first season, and since the specific growth-rate is higher in the smaller animals growth continues further into the winter, and starts earlier and is more vigorous than in B. crenatus during the second season.

There is no doubt from a comparison of the present results with those summarized above that, when growing free from competitive and other restricting environmental factors, $B$. balanoides grows more rapidly under conditions of complete immersion, at any rate when the constant depth is no greater than $3 \mathrm{ft}$. The evidence from the intertidal exposures suggests that at any level the maximum size reached is approximately the same, since by the end of the second season there is little difference at the five levels. This was a conclusion reached by Hatton \& Fischer-Piette (1932) in studying B. balanoides settled on blocks exposed intertidally. It seems, therefore, that the observation of Moore (1935b) and of Hatton (1938) that the optimum level for growth is at low water for newly settled barnacles, but moves progressively up to high water as they grow older, is due in part to the specific growthrate varying with size. The older barnacles at the top of their distribution will be growing more in their second season simply because they have grown slowly during the first, although other environmental factors, present on the shore and absent on intertidal panels kept relatively free from other growth, may play a part. 
Quite evidently it is not the unsuitability of complete submersion for growth and development that usually limits $B$. balanoides to the intertidal zone.

At all levels on the intertidal exposures, observations on barnacles other than those measured showed that maturation followed by fertilization and development of nauplii had taken place during the first season. Fertilization of $B$. balanoides in this area takes place in the autumn when the lowest mean size attained (by those on Panel III) was between II.0 and I $4.0 \mathrm{~mm}$. Other work has shown that, even though growth is much less, on the adjacent shore barnacles produce nauplii during their first year at all levels. It seems that the vegetative year observed by Runnström (I925) is due to the very low growth-rate, indicated by the small size reached at the end of the first summer's growth (some $3 \mathrm{~mm}$.). The observations of Moore (1935a) that the barnacles at the lower tidal levels matured in their first year, but at higher levels not until a year later, could possibly also be explained in this way. Again, the B. balanoides measured by Corlett (1948) had only reached a mean length of $5.9 \mathrm{~mm}$. in December, and he records that rather less than 10 \% contained developing nauplii. Neither Moore nor Corlett, however, indicate whether the sterile barnacles in question were in fact sufficiently close together to permit cross-fertilization. In our observations the high-level B. balanoides on both the pier panels and on the shore were close enough to have been fertilized by adjacent barnacles, but frequently highlevel barnacles are so scattered as to be incapable of cross-fertilization.

Further, under the conditions of these experiments, far greater sizes were attained than are usually recorded under what may be termed more natural conditions. Occasionally isolated and presumably very old individuals are found at the upper levels on the adjacent pier piles (see also Corlett), the size of which approaches those recorded here. Presumably, therefore, under natural competitive conditions death frequently intervenes before the possible maximum size is reached. It should, of course, be emphasized that, from the point of view of continued survival of the barnacle population as a whole, the isolated individuals here considered are atypical since cross-fertilization would never be achieved.

The exceptional growth of $B$. crenatus on submerged panels might be expected since it is normally a sublittoral but not a deep-water species. The sizes recorded by Barnes \& Bagenal (I95I), and indeed general experience of $B$. crenatus in the field, indicate that these maximum possible sizes are not normally reached. The environmental factors, perhaps in particular food supply, seem to be more favourable under raft conditions.

The fact that the specific growth-rates for all the Group I B. crenatus lie on a single curve, although there were 2 months between the times of settlement of Series I and IV, together with the lack of marked discontinuities in the curve, suggests that environmental conditions which varied throughout 
this period were not limiting the growth-rate. The possibility, however, cannot be ruled out that there were two different environmental factors acting in opposition. Thus, the sea temperature when Series I had reached a mean length of $12.0 \mathrm{~mm}$. was II $\cdot 0^{\circ} \mathrm{C}$., but was $15^{\circ} \mathrm{C}$. when Series IV were growing at this mean length (see Fig. I), and, although the specific growth-rates were identical, possibly an increased food supply at the lower temperature in June was equivalent to a reduced food supply for Series IV at the end of July with its higher temperature. There is some evidence that food supply becomes a limiting factor later in the season, since Series V in August, with the temperatures still comparatively high, had lower specific growth-rates than expected (from Group I data) at their mean length. Indeed the lower specific growth-rates for Group II as a whole, between August and October, even though the temperatures during this period were always higher than those in the spring, suggest that food supply may then have been a controlling factor. Lack of food also seems to be a major factor affecting growth during the winter period since the mean temperatures during January are almost as high as those during the spring, an opinion further substantiated by the increase in the specific growth-rate during the following March, when food becomes available with the advent of the spring diatom increase.

\section{SUMMARY}

The length, breadth, and in part the height, of individual Balanus balanoides and $B$. crenatus have been measured over several seasons, and the mean specific growth-rates calculated. The $B$. balanoides had settled at various known intertidal levels, and both species under conditions of permanent submersion.

Under all conditions, except on the highest intertidal panels, length increases rapidly subsequent to settlement and during the early summer. $B$. crenatus can reach its virtual maximum size $(20-25 \mathrm{~mm}$. rostro-carinal length) in a single growing season, under the conditions studied. Late-settled $B$. crenatus continue to grow further into the autumn, and begin to grow again early in the spring of the second season at the end of which the virtual maximum size is reached. The seasonal growth of both intertidal and submerged $B$. balanoides is similar, but the growth-rate is a function of submersion, which is, of course, dependent upon the tidal level. However, maximum growth is not reached in the first season and there is consequently relatively more growth in the second season than in B. crenatus.

The mean specific growth-rates in both species decrease with increasing size and, with permanently submerged $B$. crenatus, there is no suggestion that during the first spring and early summer any change in the environmental factors was effective. On the intertidal panels, the mean specific growth-rates at a given size vary with the tidal level, and this effect is most marked in the smaller barnacles. 
The ratio of length to breadth decreases, at first rapidly, then more slowly, with increase in length in both species, so that the outline of the base approaches that of a circle. The relation varies according to the tidal level. The height measurements were less satisfactory, but it is evident that the ratio increases with increasing size, the barnacles becoming relatively squatter.

The net settlement of $B$. balanoides on the intertidal panels was maximal at about mid-tide level, and it is suggested that this is the result of two opposing factors, namely, gain due to settlement when the tide crosses the panel and loss due to desiccation during exposure to air. The hypothesis is based upon the suggestion that the cyprids of an intertidal species such as $B$. balanoides settle most readily from relatively thin layers of water draining from solid surfaces.

A high incidence of infection by Hemioniscus balani was noted in the intertidal B. balanoides in the second season.

A comparison with the results of other workers shows that the growthrates recorded and sizes reached on these experimental exposures are far greater than have hitherto been observed under natural conditions, although the seasonal growth cycle is similar over a wide area. In B. balanoides it is clearly not the unsuitability of complete submersion for growth and development that usually limits this species to the intertidal zone.

\section{REFERENCES}

Admiralty Tide Tables for 1951, European Waters, Pts. I and II, I950; do. for 1952, I95I. Admiralty, London.

BARNES, H. \& BAgenal, T. B., I95I. Observations on Nephrops norvegicus (L.) and on an epizoic population of Balanus crenatus Brug. Fourn. Mar. Biol. Assoc., Vol. 30, pp. 369-80.

Barnes, H. \& Crisp, D. J., I953. (In the Press.)

BARNeS, H., CRISP, D. J. \& POWELl, H. T., I95I. Observations on the orientation of some species of barnacles. Fourn. Anim. Ecol., Vol. 20, pp. 227-4I.

CoRLETT, J., I948. Rates of settlement and growth of the 'pile' fauna of the Mersey estuary. Proc. Liverpool Biol. Soc., Vol. 56, pp. 2-28.

Darwin, C. R., 1854. A Monograph of the Sub-Class Cirripedia. London: Ray Society.

FULLER, J. L., 1946. Season of attachment and growth of sedentary marine organisms at Lamoine, Maine. Ecology, Vol. 27, pp. I50-58.

Hatton, H., I938. Essais de bionomie explicative sur quelques espèces intercotidales d'algues et d'animaux. Ann. Inst. océanogr., N.S., T. I7, Fasc. 5, pp. 24I-348.

Hatton, H. \& Fischer-Piette, E., I932. Observations et expériences sur le peuplement des côtes rocheuses par les Cirripèdes. Bull. Inst. océanogr. Monaco, No. 592,15 pp.

Moore, H. B., I934. The biology of Balanus balanoides. I. Growth rate and its relation to size, season and tidal level. fourn. Mar. Biol. Assoc., Vol. 19, pp. $85 \mathrm{I}-68$. 
MOore, H. B., I935a. The biology of Balanus balanoides. III. The soft parts. Fourn. Mar. Biol. Assoc., Vol. 20, pp. 263-77. 1935 b. The biology of Balanus balanoides. IV. Relation to environmental factors. Fourn. Mar. Biol. Assoc., Vol. 20, pp. 279-307.

Parke, M. W. \& Moore, H. B., I935. The biology of Balanus balanoides. II. Algal infection of the shell. Fourn. Mar. Biol. Assoc., Vol. 20, pp. 49-56.

Pomerat, C. M. \& Reiner, E. R., I942. The influence of surface angle and of light on the attachment of barnacles and other sedentary organisms. Biol. Bull. Woods Hole, Vol. 82, pp. I4-25.

Pomerat, C. M. \& Weiss, C. M., I946. The influence of texture and composition of surface on the attachment of sedentary marine organisms. Biol. Bull. Woods Hole, Vol. 91, pp. 57-65.

Prenant, M., I923. Hemioniscus balani Buchholz, parasite accidentel de Chthamalus stellatus Ranz. Bull. Soc. Zool. France, T. 48, pp. 374-5.

Pyefinch, K. A., I948. Notes on the biology of cirripedes. Fourn. Mar. Biol. Assoc., Vol. 27, pp. 464-503.

RunNströM, S., I925. Zur Biologie und Entwicklung von Balanus balanoides (Linné). Bergens Mus. Aarbok, Naturv. raekke, Nr. 5, 46 pp.

Topsent, E., Igrir. Croissance et mort des balanes à Luc-sur-Mer. Ann. Inst. océanogr., T. 2, Fasc. 6, 5 pp. 